\title{
Isolation and characterization of a Rhodococcus strain able to degrade 2-fluorophenol
}

\author{
Anouk F. Duque • Syed A. Hasan • Vânia S. Bessa • \\ Maria F. Carvalho • Ghufrana Samin • \\ Dick B. Janssen • Paula M. L. Castro
}

Received: 15 October 2011 / Accepted: 31 October 2011 /Published online: 19 November 2011

(C) Springer-Verlag 2011

\begin{abstract}
A pure bacterial culture able to utilize 2fluorophenol (2-FP) as sole carbon and energy source was isolated by selective enrichment from sediments collected from a contaminated site in Northern Portugal. 16S rRNA gene analysis showed that the organism (strain FP1) belongs to the genus Rhodococcus. When grown aerobically on 2-FP, growth kinetics of strain FP1 followed the Luong model. An inhibitory effect of increasing 2-FP concentrations was observed with no growth occurring at 2FP levels higher than ca. $4 \mathrm{mM}$. Rhodococcus strain FP1 was able to degrade a range of other organofluorine compounds, including 2-fluorobenzoate, 3 -fluorobenzoate, 4-fluorobenzoate, 3-fluorophenol, 4-fluorophenol, 3fluorocatechol, and 4-fluorocatechol, as well as chlorinated compounds such as 2-chlorophenol and 4-chlorophenol. Experiments with cell-free extracts and partially purified enzymes indicated that the first step of 2-fluorophenol metabolism was conversion to 3-fluorocatechol, suggesting an unusual pathway for fluoroaromatic metabolism. To our knowledge, this is the first time that utilization of 2-FP as a growth substrate by a pure bacterial culture is reported.
\end{abstract}

Keywords 2-Fluorophenol (2-FP) - Rhodococcus sp. Biodegradation $\cdot$ Luong model $\cdot$ Monooxygenase

A. F. Duque $\cdot$ V. S. Bessa $\cdot$ M. F. Carvalho $\cdot$ P. M. L. Castro $(\varangle)$ $\mathrm{CBQF} /$ Escola Superior de Biotecnologia, Universidade Católica Portuguesa,

Rua Dr. António Bernardino de Almeida, 4200-072 Oporto, Portugal

e-mail: plcastro@esb.ucp.pt

S. A. Hasan · G. Samin • D. B. Janssen

Laboratory of Biochemistry, Groningen Biomolecular Sciences

and Biotechnology Institute, University of Groningen, Nijenborgh 4,

9747 AG Groningen, The Netherlands

\section{Introduction}

The rapid growth of industrial organic synthesis has led to the widespread production and release of xenobiotic compounds, whose fate in biological waste treatment processes and in the environment is often problematic and unknown. Halogenated compounds are frequently detected in waste streams, and their recalcitrant and toxic properties have stimulated studies on their microbial metabolism and mineralization. The biodegradation of many chlorinated organic compounds has been studied (Chaudhry and Chapalamadugu 1991; Fetzner 1998; Haggblom 1992; Janssen et al. 1994; van Pée and Unversucht 2003). The behavior of fluorinated compounds, such as fluorophenols and fluorobenzenes, has been less investigated (Key et al. 1997; Murphy et al. 2009; Murphy 2010), even though their use in agricultural and industrial processes is large, and cases of environmental contamination are becoming more frequent.

Fluorinated aromatics, including compounds with fluorophenol structural units, are used as agrochemicals (Theodorides 2006), pharmaceuticals (Dimagno and Sun 2006; Sun and Adejare 2006), and in many other open applications (Key et al. 1997). Such compounds were considered to be biologically more inert and therefore less likely to have an impact on human health or the environment. On the other hand, inert molecules tend to persist and accumulate in trophic chains and are more difficult to remove by bioremediation. Fluorinated compounds have significant biological effects as enzyme inhibitors and modifiers of cell-cell communication, and they may disrupt membrane transport and processes for energy generation (Key et al. 1997). Regardless of the little information available about biological degradation of fluoroaromatic compounds, aerobic biodegradation of fluo- 
robenzoic acids (Engesser and Schulte 1989; Harper and Blakley 1971; Oltmanns et al. 1989; Schlömann et al. 1990), fluorobenzene (Carvalho et al. 2002, 2005), and 4fluorophenol (Ferreira et al. 2008) by cultures using these compounds as the sole source of carbon and energy has been investigated.

Only a few studies related to biodegradation of 2fluorophenol (2-FP) can be found in the literature. Aerobic biotransformation of 2-FP by several Rhodococcus strains (Bondar et al. 1999; Finkelstein et al. 2000), acclimated activated sludge (Chaojie et al. 2007), Gloeophyllum striatum (Kramer et al. 2004) and Penicillium strains (Hofrichter et al. 1994; Marr et al. 1996), has been reported. In all cases, 2-FP was degraded by cometabolism in the presence of other carbon sources. Recently, a strain of Pseudonocardia benzenivorans, originally isolated from an enrichment with tetrachlorobenzene (Kampfer and Kroppenstedt 2004), was reported to grow on 4-FP as the sole carbon source and to convert 2-FP and 3-fluorophenol (3-FP) when added to a resting cells suspension (Kim et al. 2010). However, no growth of P. benzenivorans on 2-FP was found. Studies on the anaerobic transformation of 2-FP and 3 -FP by methanogenic cultures and by a 2 -chlorophenoldegrading anaerobic consortium have also appeared (Londry and Fedorak 1993; Sharak Genthner et al. 1989; 1990). To our knowledge, growth of a pure bacterial culture on 2FP has not been yet reported. This work describes the enrichment, isolation, and characterization of a strain able to degrade 2-FP and use it as sole carbon and energy source.

\section{Materials and methods}

Enrichment and isolation of a 2-FP-degrading bacteria

Soil and rhizosphere samples collected from a contaminated site in Northern Portugal, which has received the discharge of chemical industry effluents for more than 50 years (fine chemistry, agrochemicals), were combined as the initial inocula for the 2-FP enrichments. This soil (approximately $5 \mathrm{~g}$ ) was used to inoculate $250-\mathrm{ml}$ flasks containing $50 \mathrm{ml}$ of sterile mineral salts medium (MM) (Caldeira et al. 1999) and 2-FP supplied as the sole carbon and energy source at a concentration of $0.44 \mathrm{mM}$. Cultures were incubated in an orbital shaker $(100 \mathrm{rpm})$ at $25{ }^{\circ} \mathrm{C}$. Half of the suspension was removed and replaced with fresh medium at 6- to 7-day intervals. Growth was monitored by measuring the optical density (OD) at $450 \mathrm{~nm}$ and liberation of fluoride was monitored using an ion-selective electrode. Bacterial strains in the degrading culture were purified by repetitive streaking onto nutrient agar (NA) medium (Lab M). These pure cultures were then re-inoculated into MM containing
$0.44 \mathrm{mM}$ of 2-FP as the sole carbon source. To confirm the capacity to grow on 2-FP, growth and fluoride releases were again monitored. One strain, designated FP1, able to degrade 2-FP as a sole carbon and energy source was isolated. Strain FP1 was deposited at BCCM/LMG Bacteria Collection, Gent, Belgium (accession number LMG 26251), and at DSMZ German Collection of Microorganisms and Cell Cultures (Braunschweig, Germany) (accession number DSM 45581).

\section{Classification of the 2-fluorophenol-degrading strain}

Strain FP1 was classified by $16 \mathrm{~S}$ rRNA gene sequencing as follows. Pure bacterial colonies were suspended in $300 \mu \mathrm{l}$ of a $0.85 \%$ sodium chloride solution and incubated for 15 min at $95{ }^{\circ} \mathrm{C}$. The suspension was then kept on ice for $7 \mathrm{~min}$ and vortexed. Subsequently, the sample was centrifuged at $14,000 \mathrm{rpm}$ for $5 \mathrm{~min}$ and the supernatant was stored at $-20{ }^{\circ} \mathrm{C}$. Then, $16 \mathrm{~S}$ rRNA gene DNA was amplified with polymerase chain reaction (PCR) using the universal primers set 27f-1492r (Lane 1991) in a reaction mixture of $25 \mu \mathrm{l}$ containing 1x PCR buffer (Promega), $2.5 \mathrm{mM} \mathrm{MgCl} 2,2.5 \%$ dimethylsulfoxide, $200 \mu \mathrm{M}$ of each dNTP, 25 pmol of each primer, $1.25 \mathrm{U}$ Taq polymerase (Promega, US), and 50-100 ng of DNA. The PCR conditions were as described by Rainey et al. (1996). The reactions were carried out in a Bio-Rad iCycler thermal cycler (Bio-Rad Laboratories, Richmond, CA, USA). PCR products were purified using GE purification kit, according to the instructions of the manufacturer. Cloning of the amplicons into pGEM T-Easy vector (Promega) and sequencing was done using an Applied Biosystems type 3730xI automatic sequencer under BigDyeTM terminator cycling conditions by Macrogen Inc. (Seoul, Republic of Korea) with universal bacterial 16S rRNA primers (f27, f518, r800, and r1492 (Lane 1991)). To determine the phylogenetic affiliation, similarity searches were done using the BLAST program (Altschul et al. 1997). Phylogenetic analysis was performed to accurately determine the taxonomic position of strain FP1. For that, 16S rRNA gene sequences were aligned using the Clustal-X program (Thompson et al. 1997) and trees were constructed with PAUP* version 4.0b10 (Swofford 2003) using the neighbor-joining method (Kimura two-parameter distanceoptimized criteria). The resulting sequence was submitted to GenBank (accession number HM210775).

\section{Growth kinetics}

Strain FP1 was examined for its capacity to grow in batch culture using 1-1 flasks filled with $250 \mathrm{ml}$ of MM and 2-FP concentrations varying between 0 and $4 \mathrm{mM}$. Each flask was inoculated with a preculture of strain FP1 to an initial 
optical density at $600 \mathrm{~nm}\left(\mathrm{OD}_{600}\right)$ of about 0.05 , measured on a Helios Gamma spectrophotometer (Unicam Instruments, UK). The cultures were incubated on an orbital shaker at $150 \mathrm{rpm}$ and $25{ }^{\circ} \mathrm{C}$. Samples were taken periodically for fluoride, 2-FP, and optical density measurements. The experiments were run in triplicate and for each 2-FP concentration and average growth rates were determined. Growth rate data were fitted with nonlinear regression using SPSS statistics 17.0 (SPSS Inc., Chicago, IL, USA). Model parameters were estimated and precision was assessed by confidence intervals at $95 \%$.

\section{Metabolic versatility}

The capacity of strain FP1 to use other halogenated/ aromatic compounds was determined using batch cultures. The experiments were carried out with $30 \mathrm{ml}$ of MM supplemented with a carbon source at a final concentration of $0.5 \mathrm{mM}$ and were run in duplicate. Appropriate volumes of a preculture of strain FP1 were used to obtain an initial $\mathrm{OD}_{600}$ of 0.06 . The flasks were incubated at $25^{\circ} \mathrm{C}$ on an orbital shaker at $150 \mathrm{rpm}$. Samples were taken during 10 days for measuring $\mathrm{OD}_{600}$ and halide release.

For oxygen uptake measurements, cells were grown on MM medium with a carbon source of choice and harvested by centrifugation at $6,000 \mathrm{~g}$ for $5 \mathrm{~min}$ at $4{ }^{\circ} \mathrm{C}$. The oxygen uptake measurements were performed as described by Ferreira et al. (2008).

\section{Preparation of cell-free extract}

Cells of strain FP1 were grown in MMY medium (Ferreira et al. 2008) supplemented with 2-FP or succinate and harvested at mid-log phase by centrifugation $\left(6,000 \times g, 4{ }^{\circ} \mathrm{C}\right.$ for $30 \mathrm{~min})$. The cells were washed twice with TEMG buffer (50 mM Tris- $\mathrm{SO}_{4}, \mathrm{pH} 7.0$ ) containing $1 \mathrm{mM}$ EDTA, $1 \mathrm{mM} \beta$-mercaptoethanol, and 5\% glycerol and resuspended in the same buffer. Protease inhibitor cocktail (Mini Complete (Roche Applied Science), one tablet per 10-ml suspension) was added prior to sonication. The cells were broken using a Vibra-Cell sonicator (Sonics and Materials INC Danbury, CT, USA) with cooling on ice. To remove unbroken cells and debris, the lysate was centrifuged at $40,000 \times g$ for $60 \mathrm{~min}$. The cell-free extract thus obtained was either stored at $-80{ }^{\circ} \mathrm{C}$ or used immediately for enzyme assays. Protein concentrations were determined using the Bradford method.

Isolation of 2-fluorophenol monooxygenase

Cell-free extract $(24 \mathrm{ml}, 353 \mathrm{mg}$ protein) of 2-FP-grown cells of strain FP1 was loaded on a DEAE-Sepharose column (50 ml; Pharmacia, Uppsala, Sweden) pre- equilibrated with TEMG buffer $\left(50 \mathrm{mM}\right.$ Tris- $\mathrm{SO}_{4}, 5 \%$ glycerol, $1 \mathrm{mM} \beta$-mercaptoethanol, and $0.5 \mathrm{mM}$ EDTA, $\mathrm{pH}$ 7.0). After washing the column with two column volumes of buffer, elution was carried out with a linear gradient of $0 \%$ to $100 \%$ of $0.5 \mathrm{M}\left(\mathrm{NH}_{4}\right)_{2} \mathrm{SO}_{4}$ in the same buffer. Fractions were collected, concentrated using 10-kDa Millipore filters (Amicon, USA), and tested for oxygenase activities. Fractions containing 2-fluorophenol monooxygenase were desalted and loaded separately onto a gel filtration column (Superdex 200, $24 \mathrm{ml}$ bed volume). Proteins were eluted with a buffer $(\mathrm{pH}$ 7.0) containing $100 \mathrm{mM} \mathrm{NaCl}, 1 \mathrm{mM}$ EDTA, and $1 \mathrm{mM} \beta$ mercaptoethanol at a flow rate of $0.2 \mathrm{ml} / \mathrm{min}$. Fractions were assayed for activity. To check the purity, concentrated fractions were run on $12 \%$ sodium dodecyl sulfate (SDS)polyacrylamide gel and stained with Coomassie Brilliant Blue R-250.

\section{Enzyme assays}

Monooxygenase activity was measured in $50 \mathrm{mM}$ Tris- $\mathrm{Cl}$ buffer $(\mathrm{pH} 7.5)$ in reaction mixtures containing $1 \mathrm{mM}$ ascorbate, $5 \mu \mathrm{M}$ FAD, $3 \mu \mathrm{g}$ of flavin reductase (FpdB, purified as described by Ferreira et al. (2009)), $180 \mathrm{U} \mathrm{ml}^{-1}$ catalase (from bovine liver, Fluka), $1.2 \mathrm{mM} \mathrm{NADH}$, and $600 \mu \mathrm{M}$ of 2-FP. Incubations were carried out at $25{ }^{\circ} \mathrm{C}$. Time course conversions were carried out in $2.0 \mathrm{ml}$ and were started by the addition of NADH. Samples of $200 \mu \mathrm{l}$ were taken with time intervals of 10-25 min and quenched by addition of an equal volume of HPLC eluent (described above). Supernatants of vortexed and centrifuged samples were analyzed with HPLC. One unit of PMO activity is defined as the amount of enzyme that converts $1 \mu \mathrm{mol}$ of substrate per minute under the conditions described.

Analytical methods

For fluoride and chloride analysis, biomass was removed from culture samples by centrifugation. The concentration of fluoride ions in supernatants was measured with an ionselective combination electrode (model CH-8902, MettlerToledo GmbH, Urdorf, Switzerland), which was calibrated with $\mathrm{NaF}(0.01$ to $5 \mathrm{mM})$ in mineral salts medium. The ionic strength of the standards and of the samples was adjusted with a buffer solution, named total ionic strength adjustment solution (TISAB). The composition of the TISAB solution was $\mathrm{NaCl}(1 \mathrm{M}), \mathrm{CH}_{3} \mathrm{COOH}(0.25 \mathrm{M})$, $\mathrm{NaCH}_{3} \mathrm{COO}(0.75 \mathrm{M})$, and sodium citrate $(0.002 \mathrm{M})$. Chloride concentrations were determined using the colorimetric method described by Iwasaki et al. (1956).

Fluorophenol and fluorocatechols (3-FC) were analyzed by HPLC on an Alltima HP C18 reversed-phase column $(100 \times 2.1 \mathrm{~mm}, 3-\mu \mathrm{m}$ particle size $)$ which was used in 
connection with Jasco PU-980 pumps, a Jasco MD-910 diode array detector and a Jasco UV-2075 detector. Samples of $10 \mu \mathrm{l}$ were injected and compounds were isocratically eluted at a flow rate of $0.2 \mathrm{ml} \mathrm{min}{ }^{-1}$. The mobile phase was $70 / 30(v / v)$ acetic acid/methanol containing $0.02 \mathrm{M}$ ammonium acetate adjusted to $\mathrm{pH} 4.5$ with glacial acetic acid. Spectra of eluted peaks were recorded between 200 and $600 \mathrm{~nm}$, and the identity was established by comparison of spectra and retention times to commercial standards. Retention times were: 2-fluorophenol, $5.14 \mathrm{~min}$; catechol, $3.06 \mathrm{~min}$; 3fluorocatechol, $3.48 \mathrm{~min}$; 4-fluorocatechol, $3.90 \mathrm{~min}$.

\section{Reagents}

All chemicals used were of the highest purity grade available (Sigma-Aldrich Chemie, Steinheim, Germany; Merck, Darmstadt, Germany). 3-FC was from SigmaAldrich and 4-FC was obtained from TCI Europe.

\section{Results}

Isolation and characterization of a bacterial strain capable to degrade 2-FP

A pure bacterial culture (strain FP1) capable of aerobic growth on 2-FP was isolated after 4 months of selective enrichment. Strain FP1 was able to use the compound as the sole carbon and energy source in liquid culture. Biodegradation was detected by growth, substrate disappearance, and fluoride release. No degradation occurred in non-inoculated controls and no growth occurred in medium without the carbon source. When streaked on NA plates, small white colonies were formed which under a light microscope appeared as gram-positive, rod-shaped cells.

Inspection of $16 \mathrm{~S}$ rRNA gene trees clearly demonstrated that strain FP1 is a member of the genus Rhodococcus, forming a cluster with Rhodococcus opacus, Rhodococcus koreensis, and Rhodococcus wratislaviensis (Fig. 1). Furthermore, this cluster includes the strains Rhodococcus sp. TCH4 (acc. no. AB183439; sequence similarity 99\% over 1,423 bases) and Rhodococcus sp. TCH14 (acc. no. AB183440; sequence similarity $99 \%$ over 1,423 bases), which were both isolated from trichloroethylenecontaminated soil and are able to degrade ortho-xylene (Taki et al. 2007).

\section{Degradation of 2-FP by strain FP1}

Rhodococcus sp. strain FP1 completely degraded $1.15 \mathrm{mM}$ of 2-FP in MM in $110 \mathrm{~h}$. A typical growth curve is shown in Fig. 2. A decrease in 2-FP concentration with stoichiometric release of fluoride was observed and complete defluorination of the target compound by strain FP1 was achieved. A simultaneous increase of the biomass concentration was observed. After 2-FP was depleted, further increase in optical density at $450 \mathrm{~nm}$ up to 0.15 in $70 \mathrm{~h}$ was observed, suggesting transient accumulation of an intermediate. One of the intermediates that were found was 3-FC (Fig. 2) as identified by HPLC, although its level of accumulation varied between different cultures.

\section{Growth kinetics}

The effect of the 2-FP concentration on the growth rate of strain FP1 was measured in batch cultures at different initial 2FP concentrations (Fig. 3). An inhibitory effect with increasing 2-FP concentrations was observed at concentrations higher than $0.6 \mathrm{mM}$. Several known kinetic models, i.e., Edwards (1970), Haldane-Andrews (Andrews 1968), Monod (1949), and Luong (1987), were tested to describe the degradation behavior of strain FP1. Among them, the Luong model (Eq. 1) resulted in the best fit $\left(R^{2}=0.970\right)$ and was consequently chosen to describe the growth rate pattern of strain FP1.

$\mu=\frac{\mu_{\max } S}{K_{\mathrm{s}}+S}\left[1-\frac{S}{S_{\mathrm{m}}}\right]^{n}$

The application of the Luong model to fit growth rate data from 0 to $4 \mathrm{mM}$ of 2-FP concentration resulted in the following kinetic parameters: maximum growth rate $\left(\mu_{\max }\right)=$ $0.031 \mathrm{~h}^{-1}$, substrate saturation constant $\left(K_{\mathrm{s}}\right)=0.067 \mathrm{mM}$, maximum substrate concentration above which growth is completely inhibited $\left(S_{\mathrm{m}}\right)=4.1 \mathrm{mM}$, and parameter indicative of the relation between the growth rate and the substrate concentration $(n)=1.1$.

\section{Metabolic versatility}

The capacity of strain FP1 to use different organic compounds for growth was tested in batch cultures. Various substrates were added to MM and the cultures were inoculated with FP1 cells pre-grown on 2-FP. From the aromatic compounds tested, strain FP1 grew very well with 2-fluorobenzoate and 2chlorophenol. Both 3-fluorocatechol (3-FC) and 4fluorocatechol, which were considered possible intermediates in 2-FP degradation, also supported growth when added as the carbon source, although the medium became brown after a few days, suggesting partial oxidation of the substrate and formation of polymeric products. The bacterium also showed some degradation activity towards 3-fluorobenzoate, 4fluorobenzoate, 3-FP, 4-FP, and 4-chlorophenol. The other fluorinated compounds tested, fluorobenzene and trifluoroacetic acid, were not used as growth substrates by strain FP1 during 10 days. 
Fig. 1 Phylogenetic tree constructed with $16 \mathrm{~S}$ rRNA gene sequences from strain FP1 and sequences retrieved from GenBank database. Closest relatives were included as well as sequences from type strains of a wide range of Actinobacteria. Bacillus subtilis and Staphylococcus aureus type strains were used as outgroup. GenBank accession numbers are given for reference sequences. Bootstrap values (expressed as percentages of 1,000 replicates) $\geq 50 \%$ are shown at branch points

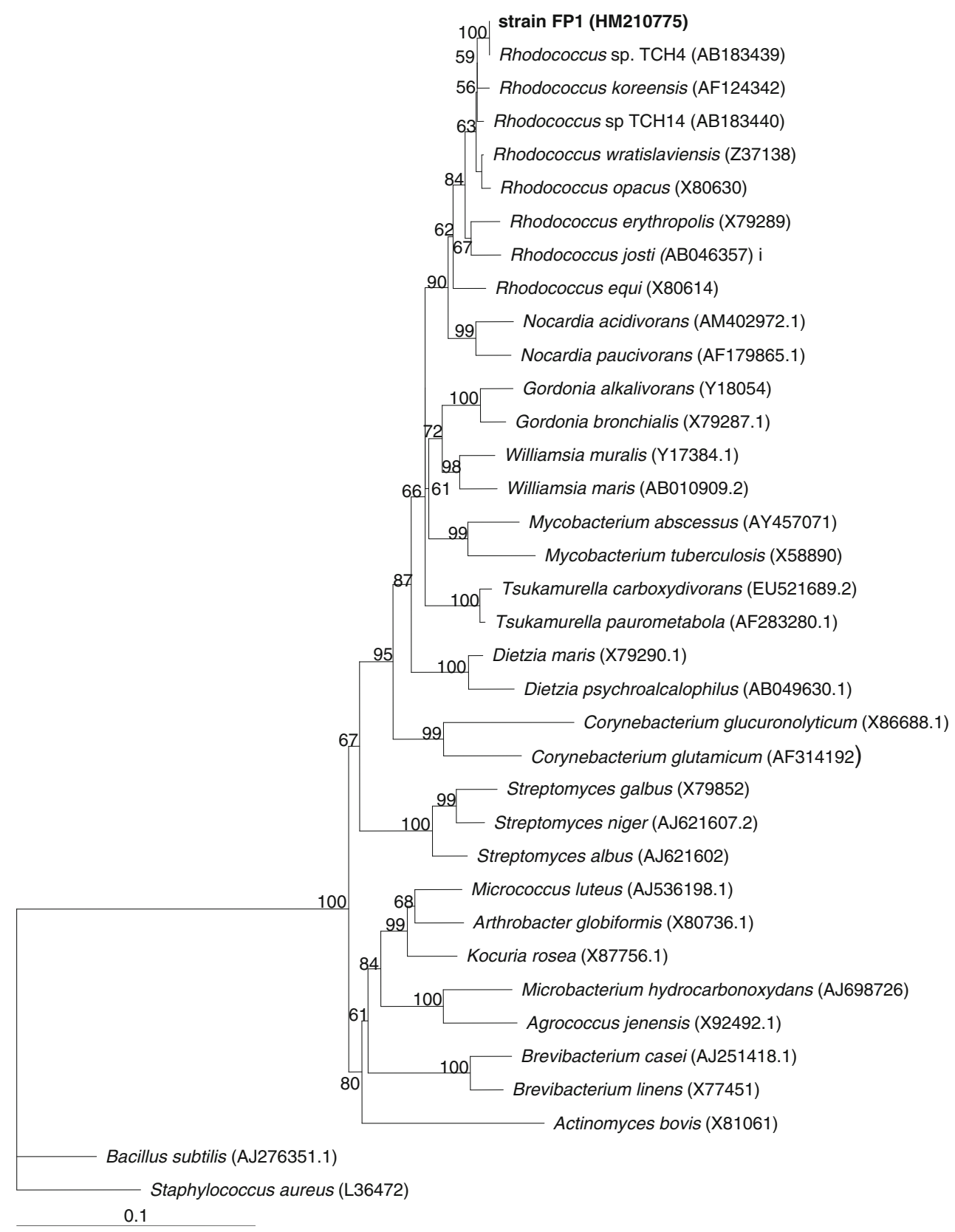

Oxidation of aromatic compounds by whole cells

To determine if enzymes for fluoroaromatic metabolism are inducible in strain FP1, oxygen uptake measurements were done. Cells of strain FP1 grown on 2-FP, 2-FP+glucose, glucose, or succinate were collected and washed and oxygen uptake was determined with 2-FP and some potential 2-FP degradation products (Table 1). Cells grown on 2-FP or 2-FP+ glucose oxidized 2-FP much faster than cells grown on glucose or succinate, indicating that the enzymes for 2-FP metabolism are induced during growth on 2-FP. Catechol and pyrogallol were also oxidized faster by cells exposed to 2-FP during growth than by cells cultivated on succinate or glucose, with pyrogallol being oxidized slower than 2-FP. The oxygen uptake rates with 3-FC were somewhat lower than with the other aromatic compounds tested but much higher with cells grown with 2-FP than in non-induced cells, suggesting that oxidative metabolism of $3-\mathrm{FC}$ is inducible by 2-FP in FP1 cells (Table 1).

Identification and isolation of a monooxygenase involved in 2-FP conversion

Bacterial conversion of several chlorophenols and 4fluorophenol can proceed by two-component monooxygenases that use NADPH as electron donor (Louie et al. 2002; Nordin et al. 2005; Ferreira et al. 2008, 2009). The reduced nicotinamide cofactor is used by the reductase component 


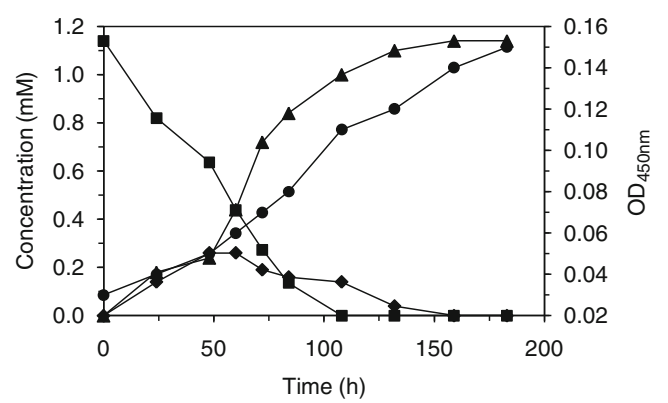

Fig. 2 Growth of strain FP1 in batch culture on $1.14 \mathrm{mM}$ of 2fluorophenol. Growth was followed over time and 2-FP and 3-FC were quantified by HPLC. Fluoride was measured with an electrode. Filled square, 2-FP concentration; filled diamond, 3-FC concentration; filled circle, optical density at $450 \mathrm{~nm}$; filled triangle, fluoride concentration

to reduce $\mathrm{FAD}$ to $\mathrm{FADH}_{2}$, which serves as the electron donor for the monooxygenase component. To investigate the possible role of such a monooxygenase in the conversion of 2-FP, we performed experiments with cell-free extracts prepared from cells grown on 2-FP, with addition of purified FAD reductase $(\mathrm{FpdB})$ from the 4-fluorophenol-degrading bacterium Arthrobacter sp. strain IF1 (Ferreira et al. 2009). Conversion was followed by HPLC analysis, which showed formation of 3-FC from 2-FP. There was no indication of formation of 4-FC or fluoride release.

To verify the presence of a 2-FP hydroxylating monooxygenase (2FP-MO) that produces $3-\mathrm{FC}$ in cell-free extract of cells grown with 2-FP, the enzyme was isolated using a DEAE-Sepharose anion exchange column and a Superdex 200 gel filtration column as described under "Materials and methods". This yielded a purified protein with specific activity, $9.5 \mathrm{U} / \mathrm{mg}$ (Fig. 4; Table 2). The flavin reductase was strictly needed for monooxygenase activity. The monooxygenase was highly induced in cells grown with 2-FP and its molecular weight was estimated at $61 \mathrm{kDa}$ by SDS-PAGE, which is close to the hydroxylase component of other two-component monooxygenases in-

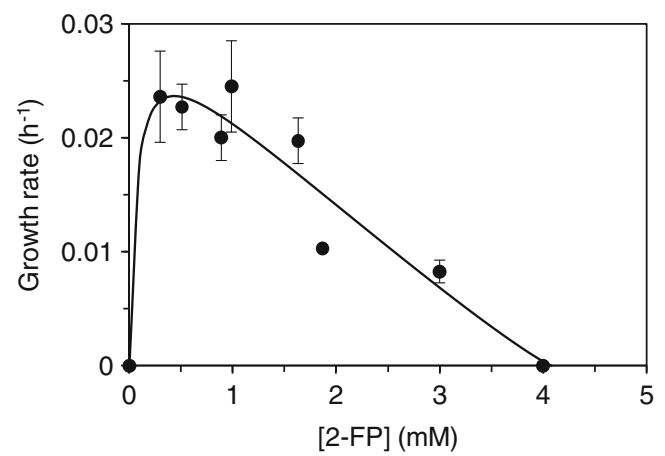

Fig. 3 Growth kinetics of strain FP1 on 2-FP. The solid line represents Luong equation plotted with $\mu_{\max }=0.031 \mathrm{~h}^{-1}, K_{\mathrm{s}}=$ $0.067 \mathrm{mM}, S_{\mathrm{m}}=4.080 \mathrm{mM}$, and $n=1.120$. Values are means \pm standard error of the mean
Table 1 Oxygen uptake by Rhodococcus sp. strain FP1 induced with different carbon sources and inoculated with selected substrates

\begin{tabular}{|c|c|c|c|c|}
\hline \multirow[t]{2}{*}{ Assay substrate } & \multicolumn{4}{|c|}{$\begin{array}{l}\text { Oxygen uptake by whole cells grown with } \\
\text { different carbon sources (nmol } \mathrm{min}^{-1} \mathrm{mg}^{-1} \text { cells) }\end{array}$} \\
\hline & 2-FP & 2-FP+glucose & Glucose & Succinate \\
\hline 2-FP & 15.3 & 5.38 & 1.93 & 0.56 \\
\hline $3-\mathrm{FC}$ & 4.90 & ND & 0.68 & 1.06 \\
\hline Catechol & 54.6 & 71.1 & 2.46 & 0.78 \\
\hline Pyrogallol & 7.33 & 6.87 & 2.32 & 0.91 \\
\hline
\end{tabular}

$N D$ not determined

volved in halophenol metabolism (Gisi and Xun 2003; Ferreira et al. 2009).

Purified 2FP-MO from fractions of the Superdex 200 chromatography column stoichiometrically transformed 2FP into 3-FC with no release of fluoride (Fig. 5). No 4fluorocatechol was detected in these assays. Transformation of 2-FP with 2FP-MO was only possible when the flavin reductase was also added to the reaction mixture containing FAD, NADH, and 2-FP. This clearly indicated that the transformation of 2-FP indeed was catalyzed by a twocomponent monooxygenase system of which one component (i.e., flavin reductase) provides reduced flavin adenine dinucleotide $\left(\mathrm{FADH}_{2}\right)$ to the other (i.e., 2FP-MO).

\section{Discussion}

In the present study, we report the isolation and properties of Rhodococcus strain FP1, a bacterial strain able to

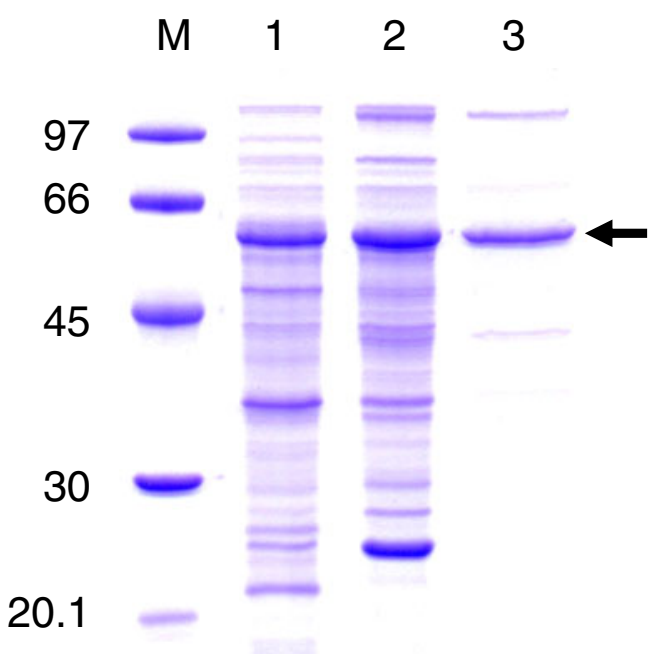

Fig. 4 SDS-PAGE of purification steps of 2FP-MO from Rhodococcus sp. strain FP1. Lane M, marker proteins; lane 1, cell-free extract of FP1 cells grown with 2-FP; lane 2, DEAE-Sepharose fraction with the highest 2FP-MO activity; lane 3, Superdex 200 fraction of PMO. Arrow indicates the 2FP-MO 
Table 2 Purification of phenol 2-monooxygenase from Rhodococcus sp. strain FP1 grown in 2-FP

\begin{tabular}{llclrr}
\hline Step & Total volume $(\mathrm{ml})$ & Total protein $(\mathrm{mg})$ & Specific activity $\left(\mathrm{U} \mathrm{mg}^{-1}\right)$ & Yield (\%) & Purification (fold) \\
\hline Cell extract & 24 & 353 & 0.54 & 100 & 1 \\
DEAE-Sepharose & 15 & 111 & 0.70 & 78 & 1.3 \\
Superdex 200 & 4 & 2 & 9.50 & 74 & 17.5 \\
\hline
\end{tabular}

degrade 2-FP as a sole source of carbon and energy. The genus Rhodococcus is regarded as one of the most versatile groups of bacteria for the biodegradation of xenobiotic and hydrophobic compounds (Warhurst and Fewson 1994). Rhodococcus strains are known to degrade aliphatic and aromatic hydrocarbons, halogenated compounds including chlorinated biphenyls, nitroaromatics, heterocyclic compounds, nitriles, and various herbicides (Martínková et al. 2009). The present paper extends this to fluorophenols. Rhodococcus strain FP1 grew and showed degradation activity towards other aromatic compounds, such as 2-fluorobenzoate, 3-FP, and 4-FP, and could utilize also 4-fluorocatechol and 3-fluorocatechol for growth, which were considered possible intermediates in 2-FP degradation.

The growth rate of Rhodococcus strain FP1 increased with increasing 2-FP concentrations, but above $0.6 \mathrm{mM} 2-$ FP was found to become inhibitory. The kinetic behavior could be described with the Luong model, with a $\mu_{\max }$ of $0.031 \mathrm{~h}^{-1}$. This model was also used for describing the kinetics of bacterial growth on fluorobenzene (Carvalho et al. 2005). The Luong parameter values for strain FP1 growing on 2-FP indicate that 2-FP is already becoming inhibitory at levels that are a little higher than $K_{\mathrm{s}}$ (0.067 mM), but that growth is completely blocked only at a much higher level $(4.1 \mathrm{mM})$, suggesting that the organism can degrade 2-FP at a quite broad range of

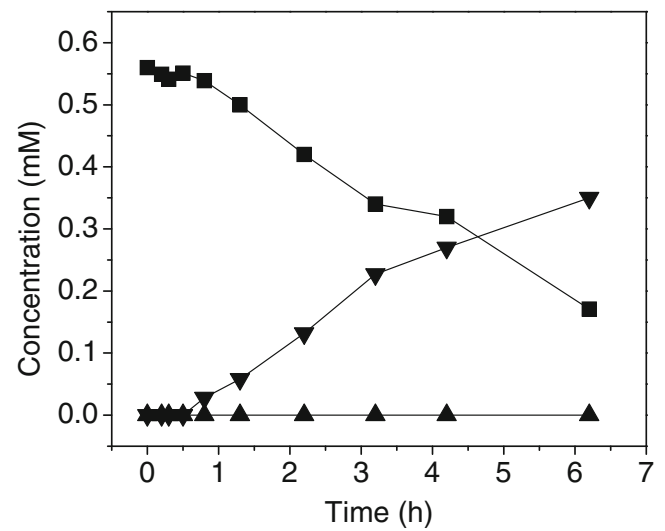

Fig. 5 Transformation of 2-FP incubated with purified 2FP-MO of Rhodococcus sp. strain FP1. Filled square, 2-FP; filled inverted triangle, 3-FC; filled triangle, $\mathrm{F}^{-}$concentration. Both 2-FP and 3-FC were determined by HPLC. Fluoride was measured by ion chromatography concentrations, albeit at low rates. The high value reached for $n(>1)$ indicates a rapid initial drop in the growth rate when the 2-FP concentration exceeds $1 \mathrm{mM}$, followed by a slow decrease to zero, suggesting a strong inhibitory effect by 2-FP (Luong 1987).

The toxicity of high levels of 2-FP could possibly be due to the formation of 3-FC, which occasionally appeared as an intermediate during growth of strain FP1 on 2-FP in batch culture. Measurements of oxygen uptake rates revealed that 3 -FC caused oxygen uptake by 2-FP-induced resting cells of strain FP1, albeit at a lower rate than with 2FP. Even though 3-FC can be oxidized and used as a growth substrate by strain FP1, a catabolic route of 2-FP via $3-\mathrm{FC}$ was first considered unlikely since $3-\mathrm{FC}$ is a known toxic compound. It was found to act as an inhibitor of metacleaving catechol 2,3-dioxygenases (Bartels et al. 1984), and recently the inhibition of growth of Sphingobium fuliginis strain TIK on 4-tert-butylphenol by 3-FC was attributed to the inhibition of the meta pathway (Toyama et al. 2010). Also, the ortho pathway may be ineffective, and the low growth rate of Acinetobacter calcoaceticus with 3FC as compared to growth on 2-fluorobenzoate was explained by poor cleavage of 3-FC by catechol 1,2dioxygenase (Clarke et al. 1975; Dorn and Knackmuss 1978). Toxicity of 2-FP reported for Pseudomonas sp. B13 growing on 3-fluorobenzoate was proposed to be due to the intradiol dioxygenation of 3-FC to yield 2-fluoro-cis,cismuconate, which was not further metabolized and caused growth inhibition (Schreiber et al. 1980). In agreement with the observed toxicity of 3-FC, it was found that bacteria growing on fluorobenzoates (Engesser et al. 1990) or fluorobenzene (Carvalho et al. 2005) convert their growth substrates via 4-fluorocatechol instead of 3-fluorocatechol. On the other hand, conversion of 2-fluoromuconate to 5fluoromuconolactone followed by dehalogenation to cisdienelactone has been found in $R$. opacus $1 \mathrm{cp}$, which also readily converts 3 -fluorocatechol to 2-fluoromuconate (Solyanikova et al. 2003). Thus, the toxicity of 3-FC may vary a lot among different organisms and is likely dependent on the specificity and activity of the enzymes of haloaromatic metabolism in a specific strain.

In view of the toxicity of 3-FC, it was unexpected that strain FP1 uses 3-fluorocatechol as a productive intermediate. One way to avoid the formation of 3-fluorocatechol would have been the replacement of the ortho fluorine by a 
hydroxyl group, which happened in Rhodococcus strains cometabolizing 2,3-difluorophenol, probably through hydroxylation (Bondar et al. 1998, 1999). Similarly, cometabolic hydroxylation of 2-FP by bacteria and fungi at the C2 and C6 positions at a ratio of 80:20 (Bondar et al. 1999), 29:71 (Peelen et al. 1995), 50:50 (Kramer et al. 2004), and 9:91 (Marr et al. 1996) yielded mixtures of catechol and 3-fluorocatechol, the former with concomitant release of fluoride. Although a similar defluorination of 2FP was not observed with Penicillium frequentans (Hofrichter et al. 1994), these findings show that catechol formation with concomitant defluorination is mechanistically possible for 2-FP. Defluorination prior to ring cleavage also occurs during biodegradation of 4fluorophenol (Ferreira et al. 2008). The observation that $3-\mathrm{FC}$ is very toxic in other organisms of course does not rule out the possibility that strain FP1 possesses enzymes that allow its metabolism at a rate sufficient for productive metabolism when it is formed as an intermediate during 2FP degradation.

Even though hydroxylation to 4-fluorocatechol and monohydroxylation with concomitant defluorination present alternatives to formation of 3-FC from 2-FP, our results show that 3-FC is the predominant intermediate in 2-FP metabolism. Apparently, the isolated 2-fluorophenol monooxygenase catalyzes a 6-hydroxylation of 2-FP. We propose that $3-\mathrm{FC}$ is converted by ortho cleavage, yielding 2fluoromuconolactone. Experiments to identify the enzymes responsible for further conversion are under way. The degradation of 2-chlorophenol and 3-chlorocatechol via ortho cleavage and subsequent dehalogenation is well established (Moiseeva et al. 2002), and a similar pathway may operate in strain FP1 for fluorocatechol. The initial 6hydroxylation appears to be catalyzed by a highly induced 2-FP monooxygenase that belongs to a class of monooxygenase systems that consist of a reductase that reduces FAD at the expense of NADH and a hydroxylase that uses free $\mathrm{FADH}_{2}$ and molecular oxygen for substrate hydroxylation (Webb et al. 2010). These enzymes are classified as class D flavoprotein monooxygenases (two-component flavin-diffusible monooxygenases) (van Berkel et al. 2006). The observation that FP1 is able to grow on 3-FC, the fact that 3-FC stimulates oxygen uptake by resting cells, and the observed formation of 3-FC by purified 2FP-MO strongly suggest that $3-\mathrm{FC}$ is the productive intermediate. We suspect that further metabolism proceeds by catechol 1,2-dioxygenase and that strain FP1 contains enzymes for the metabolism of 2-fluoromuconic acid. The observed induction shows that strain FP1 not only produces an enzymatic pathway that can convert 2-FP and 3-FC with release of fluoride but also one or more regulatory proteins that sense the presence of 2-FP and respond by increasing gene expression.
Acknowledgments A.F. Duque and M.F. Carvalho wish to acknowledge a research grant from Fundação para a Ciência e Tecnologia (FCT), Portugal (Ref. SFRH/BD/30771/2006 and SFRH/BPD/44670/2008, respectively) and Fundo Social Europeu (FSE) (Programa Operacional Potencial Humano (POPH), Quadro de Referência Estratégico Nacional (QREN)). This work was supported by FCT POCI/V.5/ A0105/2005 and PTDC/BIO/67306/2006. S.A. Hasan and G. Samin acknowledge the financial support of Higher Education Commission (HEC), Government of Pakistan. The authors are grateful to Dr. Isabel Henriques who provided support on the phylogenetic analysis and to Dr. Teresa Brandão who provided support on the application of kinetic models.

\section{References}

Altschul SF, Madden TL, Schäffer AA, Zhang J, Zhang Z, Miller W, Lipman DJ (1997) Gapped BLAST and PSI-BLAST: a new generation of protein database search programs. Nucleic Acids Res 25:3389-3402

Andrews JF (1968) A mathematical model for the continuous culture of microorganisms utilizing inhibitory substrates. Biotechnol Bioeng 10:707-723

Bartels I, Knackmuss H-J, Reineke W (1984) Suicide inactivation of catechol 2,3-dioxygenase from Pseudomonas putida $\mathrm{mt}-2$ by 3halocatechols. Appl Environ Microbiol 47:500-505

Bondar VS, Boersma MG, Golovlev EL, Vervoort J, Van Berkel WJH, Finkelstein ZI, Solyanikova IP, Golovleva LA, Rietjens IMCM (1998) 19F NMR study on the biodegradation of fluorophenols by various Rhodococcus species. Biodegradation 9:475-486

Bondar VS, Boersma MG, van Berkel WJH, Finkelstein ZI, Golovlev EL, Baskunov BP, Vervoort J, Golovleva LA, Rietjens IMCM (1999) Preferential oxidative dehalogenation upon conversion of 2-halophenols by Rhodococcus opacus 1G. FEMS Microbiol Lett 181:73-82

Caldeira M, Heald SC, Carvalho MF, Vasconcelos I, Bull AT, Castro PML (1999) 4-Chlorophenol degradation by a bacterial consortium: development of a granular activated carbon biofilm reactor. Appl Microbiol Biotechnol 52:722-729

Carvalho MF, Alves CC, Ferreira MI, De Marco P, Castro PML (2002) Isolation and initial characterization of bacterial consortia able to mineralize fluorobenzene. Appl Environ Microbiol 68:102-105

Carvalho MF, Ferreira Jorge R, Pacheco CC, De Marco P, Castro PML (2005) Isolation and properties of a pure bacterial strain capable of fluorobenzene degradation as sole carbon and energy source. Environ Microbiol 7:294-298

Chaojie Z, Qi Z, Ling C, Yuan Y, Hui Y (2007) Degradation of monofluorophenols by an acclimated activated sludge. Biodegradation 18:51-61

Chaudhry GR, Chapalamadugu S (1991) Biodegradation of halogenated organic-compounds. Microbiol Rev 55:59-79

Clarke KF, Callely AG, Livingstone A, Fewson CA (1975) Metabolism of monofluorobenzoates by Acinetobacter calcoaceticus N. C.I.B. 8250. Biochem Biophys Acta 404:169-179

Dimagno SG, Sun H (2006) The strength of weak interactions: aromatic fluorine in drug design. Curr Top Med Chem 6:14731482

Dorn E, Knackmuss H-J (1978) Chemical structure and biodegradability of halogenated compounds. Substituent effects on 1,2dioxygenation of catechol. Biochem J 174:85-94

Edwards VH (1970) The influence of high substrate concentration on microbial kinetics. Biotechnol Bioeng 12:679-712 
Engesser KH, Schulte P (1989) Degradation of 2-bromo-, 2-chloro-, and 2-fluorobenzoate by Pseudomonas putida CLB 250. FEMS Microbiol Lett 51:143-147

Engesser KH, Auling G, Busse J, Knackmuss HJ (1990) 3Fluorobenzoate enriched bacterial strain FLB-300 degrades benzoate and all three isomeric monofluorobenzoates. Arch Microbiol 153:193-199

Ferreira MIM, Marchesi JR, Janssen DB (2008) Degradation of 4fluorophenol by Arthrobacter sp. strain IF1. Appl Microbiol Biotechnol 78:709-717

Ferreira MI, Iida T, Hasan SA, Nakamura K, Fraaije MW, Janssen DB, Kudo T (2009) Analysis of two gene clusters involved in the degradation of 4-fluorophenol by Arthrobacter sp. strain IF1. Appl Environ Microbiol 75:7767-7773

Fetzner S (1998) Bacterial dehalogenation. Appl Microbiol Biotechnol 50:633-657

Finkelstein ZI, Baskunov BP, Boersma MG, Vervoort J, Golovlev EL, van Berkel WJH, Golovleva LA, Rietjens IMCM (2000) Identification of fluoropyrogallols as new intermediates in biotransformation of monofluorophenols on Rhodococcus opacus 1cp. Appl Environ Microbiol 66:2148-2153

Gisi MR, Xun L (2003) Characterization of chlorophenol 4monooxygenase (TftD) and NADH:flavin adenine dinucleotide oxidoreductase (TftC) of Burkholderia cepacia AC1100. J Bacteriol 185:2786-2792

Haggblom MM (1992) Microbial breakdown of halogenated aromatic pesticides and related-compounds. FEMS Microbiol Rev 103:29-72

Harper DB, Blakley ER (1971) The metabolism of p-fluorobenzoic acid by a Pseudomonas sp. Can J Microbiol 17:1015-1023

Hofrichter M, Bublitz F, Fritsche W (1994) Unspecific degradation of halogenated phenols by the soil fungus Penicillium frequentans Bi 7/2. J Basic Microbiol 34:163-172

Iwasaki I, Utsumi S, Hagino K, Ozawa T (1956) A new spectrophotometric method for the determination of small amounts of chloride using the mercury thiocyanate method. J Chem Soc Jpn 29:860-864

Janssen DB, Pries F, van der Ploeg JR (1994) Genetics and biochemistry of dehalogenating enzymes. Annu Rev Microbiol 48:163-191

Kampfer P, Kroppenstedt RM (2004) Pseudonocardia benzenivorans sp. nov. Int J Syst Evol Microbiol 54:749-751

Key BD, Howell RD, Criddle CS (1997) Fluorinated organics in the biosphere. Environ Sci Technol 31:2445-2454

Kim E-J, Jeon J-R, Kim Y-M, Murugesan K, Chang Y-S (2010) Mineralization and transformation of monofluorophenols by Pseudomonas benzenivorans. Appl Microbiol Biotechnol 87:1569-1577

Kramer C, Kreisel G, Fahr K, Käßbohrer J, Schlosser D (2004) Degradation of 2 -fluorophenol by the brown-rot fungus Gloeophyllum striatum: evidence for the involvement of extracellular Fenton chemistry. Appl Microbiol Biotechnol 64:387-395

Lane DJ (1991) 16S/23S rRNA sequencing. In: Stackebrandt E, Goodfellow M (eds) Nucleic acid techniques in bacterial systematics. Wiley, New York, pp 115-175

Londry KL, Fedorak PM (1993) Fluorophenols and 3-fluorobenzoate in phenol-degrading methanogenic cultures. Arch Microbiol 160:137-143

Louie TM, Webster CM, Xun L (2002) Genetic and biochemical characterization of a 2,4,6-trichlorophenol degradation pathway in Ralstonia eutropha JMP134. J Bacteriol 184:34923500

Luong JHT (1987) Generalization of Monod kinetics for analysis of growth data with substrate inhibition. Biotechnol Bioeng $29: 242-248$
Marr J, Kremer S, Sterner O, Anke H (1996) Transformation and mineralization of halophenols by Penicillium simplicissimum SK9117. Biodegradation 7:165-171

Martínková L, Uhnáková B, Pátek M, Nesvera J, Kren V (2009) Biodegradation potential of the genus Rhodococcus. Environ Int 35:162-177

Moiseeva OV, Solyanikova IP, Kaschabek SR, Gröning J, Thiel M, Golovleva LA, Schlömann M (2002) A new modified ortho cleavage pathway of 3-chlorocatechol degradation by Rhodococcus opacus 1CP: genetic and biochemical evidence. J Bacteriol 184:5282-5292

Monod J (1949) The growth of bacterial cultures. Annu Rev Microbiol 3:371-394

Murphy CD (2010) Biodegradation and biotransformation of organofluorine compounds. Biotechnol Lett 32:351-359

Murphy CD, Clark BR, Amadio J (2009) Metabolism of fluoroorganic compounds in microorganisms: impacts for the environment and the production of fine chemicals. Appl Microbiol Biotechnol 84:617-629

Nordin K, Unell M, Jansson JK (2005) Novel 4-chlorophenol degradation gene cluster and degradation route via hydroxyquinol in Arthrobacter chlorophenolicus A6. Appl Environ Microbiol 71:6538-6544

Oltmanns RH, Muller R, Otto MK, Lingens F (1989) Evidence for a new pathway in the bacterial degradation of 4-fluorobenzoate. Appl Environ Microbiol 55:2499-2504

Peelen S, Rietjens IMCM, Boersma MG, Vervoort J (1995) Conversion of phenol derivatives to hydroxylated products by phenol hydroxylase from Trichosporon cutaneum. A comparison of regioselectivity and rate of conversion with calculated molecular orbital substrate characteristics. Eur J Biochem 227:284-291

Rainey FA, Ward-Rainey N, Kroppenstedt RM, Stackebrandt E (1996) The genus Nocardiopsis represents a phylogenetically coherent taxon and a distinct actinomycete lineage: proposal of Nocardiopsaceae fam. nov. Int J Syst Bacteriol 46:1088-1092

Schlömann M, Fischer P, Schmidt E, Knackmuss HJ (1990) Enzymatic formation, stability, and spontaneous reactions of 4fluoromuconolactone, a metabolite of the bacterial degradation of 4-fluorobenzoate. J Bacteriol 172:5119-5129

Schreiber A, Hellwig M, Dorn E, Reineke W, Knackmuss HJ (1980) Critical reactions in fluorobenzoic acid degradation by Pseudomonas sp. B13. Appl Environ Microbiol 39:58-67

Sharak Genthner BR, Townsend GT, Chapman PJ (1989) Anaerobic transformation of phenol to benzoate via paracarboxylation: use of fluorinated analogues to elucidate the mechanism of transformation. Biochem Biophys Res Commun 162:945-951

Sharak Genthner BR, Townsend GT, Chapman PJ (1990) Effect of fluorinated analogues of phenol and hydroxybenzoates on the anaerobic transformation of phenol to benzoate. Biodegradation $1: 65-74$

Solyanikova IP, Moiseeva OV, Boeren S, Boersma MG, Kolomytseva MP, Vervoort J, Rietjens IM, Golovleva LA, van Berkel W (2003) Conversion of 2-fluoromuconate to cis-dienelactone by purified enzymes of Rhodococcus opacus 1cp. Appl Environ Microbiol 69:5636-5642

Sun S, Adejare A (2006) Fluorinated molecules as drugs and imaging agents in the CNS. Curr Top Med Chem 6:1457-1464

Swofford DL (2003) PAUP*. Phylogenetic analysis using parsimony (and other methods). Version 4.0 d10. Sinauer, Sunderland

Taki H, Syutsubo K, Mattison RG, Harayama S (2007) Identification and characterization of $o$-xylene-degrading Rhodococcus spp. which were dominant species in the remediation of $o$-xylenecontaminated soils. Biodegradation 18:17-26 
Theodorides G (2006) Fluorine-containing agrochemicals. In: Tressaud A (ed) Advances in fluorine science, vol 2. Elsevier, Amsterdam, pp 121-175

Thompson JD, Gibson TJ, Plewniak F, Jeanmougin F, Higgins DG (1997) The Clustal X windows interface: flexible strategies for multiple sequence alignment aided by quality analysis tools. Nucleic Acids Res 49:269-279

Toyama T, Momotani N, Ogata Y, Miyamori Y, Inoue D, Sei K, Mori K, Kikuchi S, Ike M (2010) Isolation and characterization of 4tert-butylphenol-utilizing Sphingobium fuliginis strains from Phragmites australis rhizosphere sediment. Appl Environ Microbiol 76:6733-6740 van Berkel WJH, Kamerbeek NM, Fraaije MW (2006) Flavoprotein monooxygenases, a diverse class of oxidative biocatalysts. J Biotechnol 124:670-689

van Pée KH, Unversucht S (2003) Biological dehalogenation and halogenation reactions. Chemosphere 52:299-312

Warhurst AM, Fewson CA (1994) Biotransformations catalyzed by the genus Rhodococcus. Crit Rev Biotechnol 14:29-73

Webb BN, Ballinger JW, Kim E, Belchik SM, Lam KS, Youn B, Nissen MS, Xun L, Kang C (2010) Characterization of chlorophenol 4-monooxygenase (TftD) and NADH:FAD oxidoreductase (TftC) of Burkholderia cepacia AC1100. J Biol Chem 285:2014-2027 